\title{
HORMONAL REGULATION OF MEMBRANE PHENOTYPE IN HEPATOMA CELLS*
}

\author{
Thomas D. Gelehrter \\ Departments of Internal Medicine and Human Genetics \\ University of Michigan Medical School \\ Ann Arbor, Michigan 48109
}

Glucocorticoids affect the composition and function of the plasma membrane in a variety of cell types. ${ }^{1}$ Incubation of HTC cells, an established line of rat hepatoma cells in tissue culture, with the synthetic glucocorticoid dexamethasone (DEX) alters several membrane properties characteristic of transformed cells, without affecting the growth rate of these cells. Dexamethasone rapidly and reversibly inhibits the active transport of selected amino acids, ${ }^{2-6}$ increases the adhesiveness of the cells to a plastic or glass substrate by a process that requires macromolecular synthesis, ${ }^{7-9}$ and rapidly and dramatically inhibits the activity of plasminogen activator (PA), a serine protease, which may itself modulate other membrane properties. ${ }^{10-14}$

HTC cells provide a favorable experimental system for the investigation of the hormonal regulation of membrane phenotype. The effects of individual hormones, either in isolation or in combination, can be studied in a fashion that is not possible in the intact animal. An established cell line offers the ease of experimental manipulation and stability under a variety of experimental conditions, not usually available in freshly-isolated dissociated cells or in primary cultures of liver cells. The ability to grow HTC cells in suspension culture reduces the need for manipulations such as trypsinization, which can affect transport and other membrane processes. HTC cells have been studied intensively with regard to glucocorticoid receptor function and induction of tyrosine aminotransferase (TAT), ${ }^{15,16}$ which further enhances their usefulness for our studies. Finally, as discussed in this communication, it is possible to isolate steroid-resistant variant lines of HTC cells allowing the application of both genetic and biochemical techniques to the study of the hormonal regulation of membrane properties in these liver-derived cells.

\section{Glucocorticoid Regulation of Amino Acid Transport in HTC Cells}

We have studied the transport of amino acids by HTC cells in suspension culture utilizing the model amino acid $\alpha$-aminoisobutyric acid (AIB). AIB is transported in a number of tissues by the so-called A, or alanine-preferring, system for neutral amino acids. ${ }^{17}$ Following uptake, AIB is neither incorporated into protein nor catabolized; hence its transport can be studied independently of the complications introduced by such intracellular metabolism. Subsequently, we have extended our studies to the hormonal modulation of the transport of natural amino acids. HTC cells in suspension culture in a chemically-defined, serum-free medium containing

* These studies were supported by research Grants (GM 17712, GM 15419 and CA 22729) from the National Institutes of Health. TDG is the recipient of a Faculty Research Award from the American Cancer Society. 
essential amino acids and glucose, actively transport AIB by saturable, stereospecific, energy-dependent process. Distribution ratios greater than 20 are achieved at AIB concentrations of less than $0.5 \mathrm{mM}$. A single sodium-dependent transport system appears to mediate the bulk of AIB uptake. The apparent $\mathrm{Km}$ for this system is $\mathrm{l}$ to $3 \mathrm{mM}^{2.5}$

Dexamethasone rapidly and dramatically decreases the influx of AIB. Following a lag of approximately one-half hour, the initial rate of transport decreases exponentially to approximately $20 \%$ of control after 6 hours, and $10 \%$ after 18 hours incubation with hormone. Inhibition is half-maximal within 90 to 120 minutes (FIGURE 1). The inhibition of AIB transport by dexamethasone reflects a decrease in the capacity of the transport system, or its Vmax, without significant change in the apparent $\mathrm{Km}$ of the transport system. ${ }^{2,3}$ Removal of the hormone by washing and resuspension of the cells in glucocorticoid-free medium, reverses the inhibition of AIB transport. Recovery of control rates of transport occur within approximately 20 hours; half-maximal recovery requires approximately 5 to 6 hours. ${ }^{2,}$ Incubation of dexamethasone-treated cells with insulin results in a rapid, striking stimulation of AIB transport to or near control levels within 2 hours incubation. ${ }^{1,2,18}$

\section{Mechanism of Glucocorticoid Inhibition of Transport}

The mechanism of the transport inhibition has been explored using a variety of inhibitors. Neither colcemid nor cytochalasin B, at concentrations sufficient to disaggregate microtubules and microfilaments, respectively, interferes with AIB transport nor its inhibition by dexamethasone. Thus, cytoskeletal elements do not appear to play an important role in the hormonal inhibition of AIB transport. ${ }^{4}$

Complete $(>98 \%)$ inhibition of protein synthesis by $0.1 \mathrm{mM}$ cycloheximide blocks

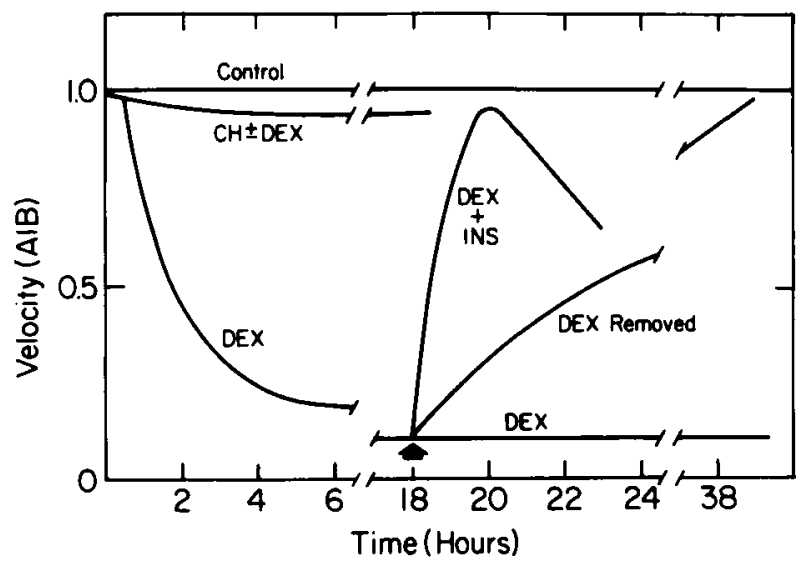

FIGURE 1. Schematic time course of the hormonal regulation of AIB transport in HTC cells. Velocity (AIB) indicates the initial rate of influx of AlB measured during a 5 to 10 minute incubation with $\left[{ }^{14} \mathrm{C}\right]$-AIB. Data are expressed on an arbitrary scale of 0 to 1.0 . Time indicates time of incubation with hormone. The arrow at 18 hours indicates addition of insulin to dexamethasone-treated cells, or removal of dexamethasone by washing and resuspension of cells in hormone-free medium. The effect of both of these experimental treatments was completely blocked by $0.1 \mathrm{mM}$ cycloheximide. Based on data from references 2,4 and 18 , plus unpublished observations. (From Gelehrter.' By permission of Springer-Verlag.) 
the dexamethasone inhibition of transport. Curiously, cycloheximide alone only minimally inhibits the uptake of AIB. Cycloheximide also blocks the recovery of AIB transport following removal of dexamethasone. Furthermore, addition of cycloheximide 30,60 , or 120 minutes after the addition of dexamethasone completely prevents any further inhibition of AIB transport by the glucocorticoid. ${ }^{4}$ Lower concentrations of cycloheximide $(1 \mu \mathrm{M})$, which inhibit amino acid incorporation into protein by $40 \%$ to $60 \%$, do not prevent the dexamethasone inhibition of AIB transport, but do inhibit transport in the absence of dexamethasone.

Studies using actinomycin D to inhibit RNA synthesis have yielded similar results. Concentrations of actinomycin $(0.2 \mu \mathrm{M})$ sufficient to inhibit the incorporation of uridine into RNA by $90 \%$ to $95 \%$, inhibit AIB transport but do not interfere with the inhibition by dexamethasone. ${ }^{4}$ Higher concentrations of actinomycin $\mathrm{D}(4 \mu \mathrm{M})$, which block uridine incorporation by more than $95 \%$ (and cause "superinduction" of tyrosine aminotransferase ${ }^{19}$ ) cause only a modest inhibition of AIB transport in control cells but completely prevent the dexamethasone inhibition of AIB transport; results similar to those obtained with $0.1 \mathrm{mM}$ cycloheximide. ${ }^{4}$

High concentrations of both cycloheximide and actinomycin $D$ have been reported to interfere with protein degradation in HTC cells and other rat hepatoma cells in tissue culture. ${ }^{20-2 d}$ We feel that the experimental results described above are most compatible with the hypothesis that dexamethasone accelerates the degradation of some rate-limiting component of the AIB transport system. In the presence of high concentrations of cycloheximide or actinomycin D, degradation is blocked, and DEX action inhibited. This explanation is also consistent with the time course of the dexamethasone inhibition and its reversal after removing dexamethasone. It should be noted that an effect on degradation would result in more rapid changes in transport than a comparable effect on the rate of synthesis, since the time course of change from one steady state to another is a function only of the rate of degradation of the relevant protein. ${ }^{24}$

\section{Steroid Specificity of the Glucocorticoid Inhibition of Transport}

We have also investigated the relationship between steroid structure and inhibition of AIB transport, and compared this with the steroid specificity of induction of tyrosine aminotransferase ${ }^{25}$ and binding to specific cytoplasmic glucocorticoid receptors. ${ }^{26}$ Our observations support the model of a common receptor system in the mechanism of action of glucocorticoids in HTC cells. Dexamethasone and cortisol, which are full agonists with respect to transaminase induction, are also full agonists with respect to transport inhibition. The concentrations required for half-maximal inhibition of transport, $5 \mathrm{nM}$ for dexamethasone and $60 \mathrm{nM}$ for cortisol, correspond almost exactly to those required for half-maximal induction of tyrosine aminotransferase. Tetrahydrocortisol, an inactive steroid because it neither binds to the cytoplasmic receptor nor induces transaminase, has no affect on either AIB transport or its inhibition by dexamethasone. Curiously, 11- $\beta$-hydroxyprogesterone and deoxycorticosterone, which are partial agonists or "suboptimal inducers" of tyrosine aminotransferase, are, at sufficiently high concentrations, full agonists with respect to transport inhibition. Even 17- $\alpha$-methyltestosterone, an "anti-inducer" of tyrosine aminotransferase, causes significant inhibition of AIB transport at high concentrations $(0.1 \mathrm{mM})$. Competition experiments, in which the effects of increasing concentrations of partial agonists or antagonists together with a constant concentration of full agonist are examined, confirm the above results. The inhibition of amino acid transport by steroids that are partial agonists or antagonists for transaminase induction is not a generalized toxic effect of high concentrations of these steroids. Rather, 
they appear to share with dexamethasone common mechanisms of action in terms of their time course, reversibility, and inhibition by cycloheximide and actinomycin D. ${ }^{27}$ These observations imply more complexity then is currently encoded in the steric-allosteric model of steroid hormone action, ${ }^{28}$ or in the nature of the postreceptor events as described by the widely accepted induction model of glucocorticoid action. ${ }^{15,16}$

\section{Role of the Nucleus in Glucocorticoid Regulation of Transport}

It is generally believed that nuclear localization of steroid-receptor complexes is necessary for their biological actions ${ }^{15}$; however, the possibility that steroid-receptor complexes may have nonnuclear actions has not been excluded. At present there is direct evidence for nuclear localization of only full agonist glucocorticoids in HTC cells, and indeed there is some evidence that antagonists or anti-inducers do not enter the nucleus. ${ }^{29}$ In order to study the possibility that the dexamethasone-receptor complex might have direct cytoplasmic actions, we have examined the dexamethasone regulation of AIB transport in anucleate HTC cells. HTC cells were enucleated by centrifugation through Ficoll gradients containing $10 \mu \mathrm{g} / \mathrm{ml}$ cytochalasin $\mathrm{B}^{30}$ Preparations of cytoplasts containing more than $96 \%$ anucleate cells in yields of approximately $60 \%$ could be obtained readily. Washed cytoplasts could be maintained in suspension in serum-free medium for more than 24 hours without loss of membrane integrity, as assessed by the exclusion of trypan blue. Anucleate HTC cells transport AIB with initial rates of uptake equal to or greater than those of intact cells, for as long as 24 hours in culture. The time course of uptake and the kinetics of AlB transport are the same as those of intact cells. Dexamethasone, however, completely fails to inhibit AIB uptake in cytoplasts. Transport was also unaffected by deoxycorticosterone and $11-\beta$-hydroxyprogesterone at concentrations that produced maximal inhibition of transport in nucleated cells. ${ }^{31,32}$ The failure of dexamethasone inhibition of transport in anucleate HTC cells could not be accounted for by the decreased level of total protein synthesis in anucleate cells, nor by absence of specific glucocorticoid receptors. Thus the nucleus appears to be required for the glucocorticoid regulation of AIB transport in HTC cells. This may reflect the requirement for direct nuclear action of glucocorticoids, or a requirement for the nucleus for the maintenance of normal rates of protein degradation. ${ }^{33}$

\section{Amino Acid Specificity of Glucocorticoid Inhibition of Transport}

Dexamethasone also inhibits the initial rates of transport of several natural amino acids. The transport of glycine, serine, alanine, and proline, amino acids transported mainly by the A system, ${ }^{17}$ was inhibited $50 \%$ to $85 \%$ by dexamethasone. Transport of amino acids thought to be transported mainly by the $\mathrm{L}$ system (phenylalanine, leucine, and valine) was also inhibited, although to a lesser extent. Detailed kinetic analysis of glycine transport by hepatoma cells revealed at least two separate transport systems. One system is characterized by low affinity $(\mathrm{Km}=5.1 \mathrm{mM})$ and high capacity for glycine transport. This system appears to be analogous to the A-transport system described in other cell types because it is sodium and $\mathrm{pH}$-dependent, and mediates the bulk of AIB transport. The other transport system is characterized by higher affinity $(\mathrm{Km}=0.23 \mathrm{mM})$ and lower capacity for glycine transport, is also sodium-dependent, but is not inhibited at low $\mathrm{pH}$. The pattern of inhibition of the latter system by various amino acids and analogs differs from that of any previously characterized transport system in animal cells. Both transport systems for glycine are 
strikingly inhibited by dexamethasone; however, the time course of the glucocorticoid inhibition of the low-affinity, high-capacity system is much more rapid. Glutamic acid uptake by HTC cells is also markedly inhibited by dexamethasone, and appears to be mediated by one or more transport agencies distinct from either of the glycine transport systems. Therefore, dexamethasone appears to inhibit the activity of at least three discrete amino acid transport systems in rat hepatoma cells. ${ }^{6}$ This finding is in contrast to the generally held belief that hormones and other modulators of transport affect solely or primarily the A system. ${ }^{34}$

\section{Glucocorticoid Regulation of Plasminogen Activator}

Many transformed cells produce increased amounts of proteolytic enzymes, such as plasminogen activator. ${ }^{35,36}$ The production of such proteases has received special attention because of the pleiotropic effects of these enzymes on membrane structure and function, and because of their important role in biological regulation. ${ }^{35-37}$ Proteolytic removal or alteration of a limited number of membrane proteins could have diverse effects on the behavior of many cell surface proteins, by influencing either their mobility within the membrane or their interaction with each other and with the interior of the cell.

Wigler $e t$ al. first reported that HTC cells produced large amounts of plasminogen activator, and that this activity is dramatically and rapidly inhibited by treatment of the cells with dexamethasone. ${ }^{10}$ We have confirmed these observations and have investigated the mechanism by which glucocorticoids inhibit the activity of this serine protease. The time course of inhibition of intracellular PA activity by dexamethasone is shown in Figure 2. PA activity is measured by the solubilization of ${ }^{125}$ I-fibrin; fibrinolytic activity in HTC cells is entirely dependent on the presence of plasminogen. Dexamethasone, after a short lag, causes a rapid inhibition of PA activity, which is maximal in 3 to 5 hours and is half-maximal after approximately 90 minutes incubation with the hormone. The direct addition of dexamethasone to the assay has no effect on fibrinolytic activity. ${ }^{12}$

The inhibition of plasminogen activator could involve a decrease in the amount of PA secondary to a decrease in its rate of synthesis or increase in its rate of degradation, or the induction of an inhibitor of PA activity, or a combination of these mechanisms. Mixing experiments were carried out in which increasing amounts of cell extracts of hormone-treated cells were incubated with a constant amount of cell extract of untreated cells as a source of PA activity. The concentration-dependent inhibition of PA activity in such mixtures revealed the presence of an inhibitory activity in dexamethasone-treated cells. ${ }^{12}$ Cell fractionation experiments indicated that PA activity is localized to the particulate $(100,000 \times \mathrm{g}$ pellet $)$ fraction whereas the inhibitory activity is found primarily in the soluble cytoplasmic fraction (100,000 $\times g$ supernatant). However, inhibitory activity is also found in the particulate fraction, and in the serum-free medium conditioned by dexamethasone-treated cells.

\section{Genetic Approaches to the Hormonal Regulation of Plasma Membrane Phenotype}

In order to investigate the mechanisms by which steroids induce the membrane changes described above, it would be helpful to have mutants or variants resistant to the regulatory effects of glucocorticoids. Since glucocorticoids do not kill or alter the growth or plating efficiency of HTC cells on plastic or in agar, ${ }^{13,38}$ there are no obvious selective systems by which to isolate dexamethasone-resistant cells. Instead, we have utilized an agar-fibrin overlay technique ${ }^{39}$ to detect the production of 


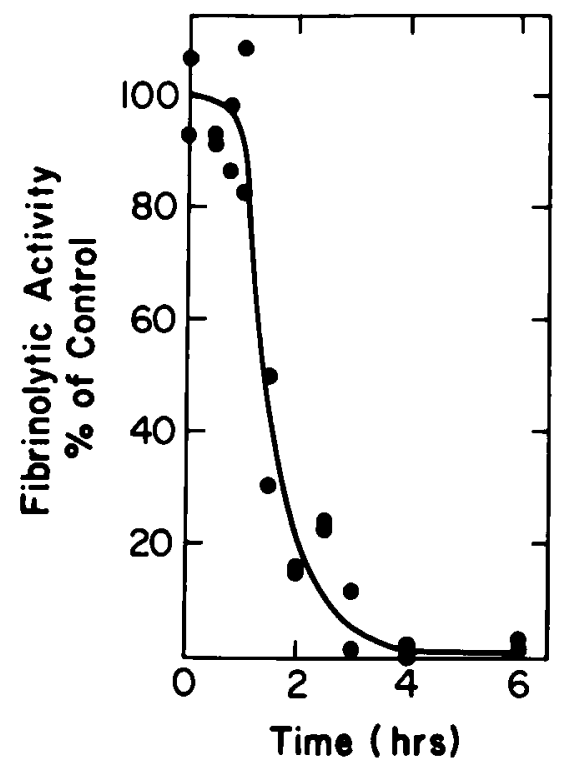

FIgURE 2. Time course of dexamethasone inhibition of plasminogen activator. HTC cells were incubated overnight in serum-free medium and then incubated in the presence or absence of $1 \mu \mathrm{M}$ dexamethasone. Triton extracts of cells were assayed on ${ }^{125} \mathrm{I}$-fibrin-coated plates, and results normalized for the amount of protein in each sample. Each point represents the average of duplicate assays on a single culture. (From Seifert \& Gelehrter. ${ }^{2}$ By permission of National Academy of Sciences.)

plasminogen activator by individual colonies of HTC cells. ${ }^{11,13}$ This technique is not selective, but it is not destructive and allows recovery of selected colonies through the agar overlay and their subsequent propagation. Nine hormone-resistant variant cell lines have been isolated. The resistant phenotype has been stably inherited in three of these variants for over 300 generations in the absence of dexamethasone. The degree of glucocorticoid resistance of these three lines is illustrated in FIGURE 3. PA activity in wild-type cells is half-maximally inhibited by $5 \mathrm{nM}$ dexamethasone and completely inhibited by concentrations greater than $10 \mathrm{nM}$. Variant cell lines are fully resistant to concentrations of dexamethasone 1,000 times those required to completely inhibit PA activity in wild-type cells. ${ }^{13}$

Each variant appears to possess distinct morphology; however, there appears to be no single consistent morphology associated with resistance to dexamethasone inhibition of PA activity. The cloning efficiencies of 3 variant lines tested is the same as that of wild-type cells (40\% to $60 \%$ ), and in no case are these efficiencies altered by dexamethasone. The growth of wild-type and variant cells in both monolayer and suspension culture appears to be the same. Thus regulation of growth and regulation of this serine protease are obviously dissociated in HTC cells. ${ }^{3,14}$

The origin of the resistant phenotype is not entirely clear. Fluctuation analyses demonstrate that the dexamethasone-resistant phenotype arises at random and is present prior to exposure to the hormone. Thus the variants are not induced by exposure to dexamethasone. On the other hand, neither chemical (ethyl methanesulfonate) nor physical (ultraviolet light) mutagens detectably increased the frequency with which the dexamethasone-resistant phenotype is observed. These observations argue against mutations as the primary cause of resistance to dexamethasone. Because 


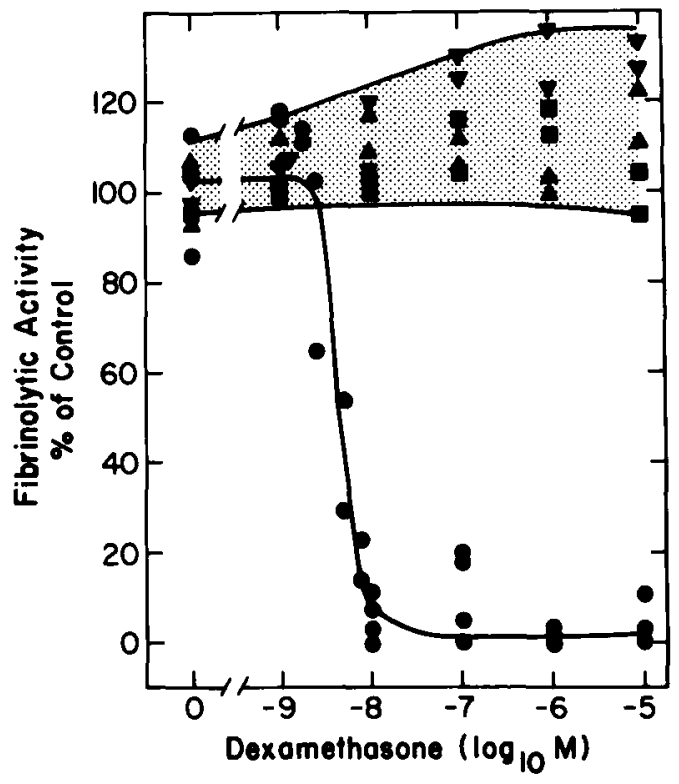

FIGURE 3. Concentration-dependence of dexamethasone inhibition of plasminogen activator in wild-type and steroid-resistant HTC cells. Cells were incubated with the concentrations of dexamethasone indicated for 18 hours, and intracellular fibrinolytic activity assayed. In order to facilitate comparison, results for each cell line are expressed as the percentage of activity of the respective untreated cells. Each point represents the average of duplicate assays performed on a single culture. Symbols: control $(\Theta)$; variant $A(\square)$; variant $B(\Delta)$; variant $C(\nabla)$. (From Seifert \& Gelehrter. ${ }^{13}$ By permission of Journal of Cellular Physiology.)

HTC cells are heteroploid and karyotypically highly variable, variants are thought to arise primarily by chromosomal segregation events. ${ }^{13}$

The mechanism of resistance to dexamethasone inhibition of plasminogen activator in the variant cell lines could be the result of a failure of the hormone to induce the inhibitor, or to the production of a plasminogen activator that is resistant to the action of the inhibitor. We have attempted to distinguish between these hypotheses by carrying out the mixing experiments shown in FIGURE 4 . In the experiment depicted in panel A, increasing amounts of an extract of dexamethasone-treated variant cells were added to a constant amount of extract of untreated wild-type cells (as a source of plasminogen activator activity). There is no evidence of any inhibition of plasminogen activator activity by the extract of dexamethasone-treated variant cells. In contrast, as shown in panel B, the addition of increasing amounts of extract of dexamethasone-treated wild-type cells to a constant amount of extract from untreated variant cells demonstrates a concentration-dependent inhibition of protease activity. These observations indicate that the plasminogen activator produced by the variant cell line is fully sensitive to inhibition by inhibitor from wild-type cells; in contrast, there appears to be no inhibitor in the dexamethasone-treated variant cell line. ${ }^{12}$ Identical results have been obtained with two other variant cell lines tested.

In contrast to most reported glucocorticoid-resistant variant cells lines, ${ }^{40,41}$ these variants are unique because resistance is not secondary to defective or absent glucocorticoid receptors. This interpretation is based on the finding that dexamethasone induces tyrosine aminotransferase to the same extent and with the same time 

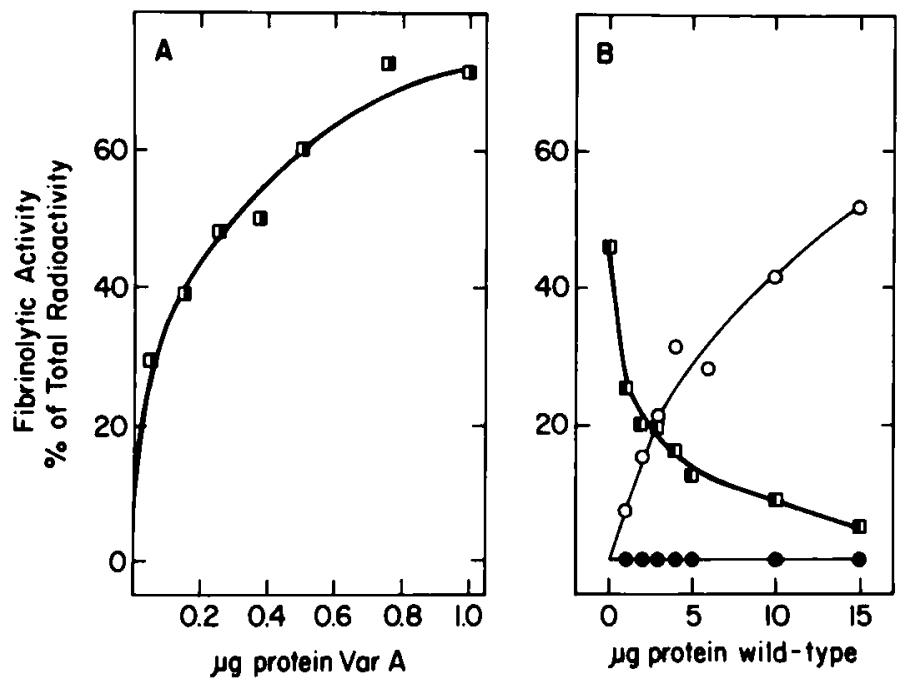

FIGURE 4. Dexamethasone induces an inhibitor of plasminogen activator in wild-type cells but not in variant cells. (A) Increasing amounts of an extract of dexamethasone-treated variant cells were mixed with a fixed amount of extract of untreated wild-type cells prior to assaying PA activity on ${ }^{125}$ I-fibrin-coated plates. (B) Increasing amounts of an extract of dexamethasonetreated wild-type cells were mixed with a fixed amount of extract of untreated variant cells prior to assaying in a similar fashion (D). Shown for comparison is the fibrinolytic activity of increasing amounts of extract of untreated $(O)$ and dexamethasone-treated $(O)$ wild-type cells assayed in the same fashion. (From Carlson \& Gelehrter." By permission of Journal of Supramolecular Structure.)

course in the variant lines as in wild-type HTC cells. ${ }^{11,13}$ Because the induction of tyrosine aminotransferase requires an intact glucocorticoid receptor capable of being translocated to the nucleus, these observations suggest that the proximal steps in the glucocorticoid receptor pathway are intact in these variants, and that the resistance is due to a more distal lesion in the pathway of hormonal inhibition of PA.

The selectivity of the hormone resistance in these variants has been studied by examining the ability of dexamethasone to inhibit AIB transport. The velocity of AIB transport by wild-type and variant cell lines in the absence of dexamethasone was similar. Eight of nine variant lines tested showed wild-type inhibition of AIB transport. ${ }^{11,13}$ Thus these variants do not show a general resistance to all membraneassociated dexamethasone responses, and it can be concluded that these two membrane properties are independently regulated by dexamethasone. Interestingly, one variant did show partial resistance to inhibition of AIB transport by dexamethasone; this resistance was manifest even at concentrations of dexamethasone as high 10 $\mu \mathbf{M}^{13}$

\section{Role of Plasminogen Activator in the Dexamethasone Regulation of Cellular Adhesiveness}

We have utilized the dexamethasone-resistant variants to analyze the mechanism of dexamethasone regulation of other membrane properties, such as the induction of adhesion in HTC cells. ${ }^{9}$ We have directly tested the hypothesis that dexamethasone 
induces cell adhesiveness by decreasing the activity of plasminogen activator, which, in turn, allows the accumulation of specific membrane glycoproteins necessary for adhesion. If this hypothesis were correct, there should be little or no dexamethasone induction of adhesion in the variant cell lines resistant to the inhibition of PA. We have reported that, in fact, dexamethasone induces the adhesiveness of three of three variant HTC cell lines tested to a similar extent as in wild-type cells. ${ }^{9,14}$ Experiments with one variant are shown in FIGURE 5. These observations suggest that the dexamethasone induction of adhesion probably operates primarily through the synthesis of cell surface glycoproteins and that this process in turn is not regulated by the inhibition of PA activity.

Thus, dexamethasone-resistant variant cell lines have been useful in studying the role of proteases in the hormonal regulation of other membrane functions. In the case of the induction of cellular adhesiveness, they have allowed the clear exclusion of a plausible hypothesis for the mechanism of induction of adhesiveness. Studies with these variants also indicate that the inhibition of AIB transport is not secondary to an inhibition of PA activity, since variants resistant to the latter effect retain normal inhibition of transport. Because these variant cell lines also retain wild-type induction of tyrosine aminotransferase as well as inhibition of amino acid transport and induction of adhesiveness, it appears the process or processes in hormonal regulation that are defective in these variants are not shared in the regulation of other hormone-induced events. Such a conclusion is also supported by our studies with Thompson et al. utilizing other HTC cell variants in which tyrosine aminotransferase is not inducible. These noninducible variants have retained wild-type glucocorticoid regulation of such membrane properties as AIB transport and PA activity. ${ }^{42}$ Cell hybridization experiments between variants resistant to enzyme induction and others resistant to the inhibition of PA activity should help in unraveling the mechanisms by which glucocorticoids regulate these functions in HTC cells. Finally, these variants provide a powerful tool for analyzing the hormonal regulation of membrane and secretory proteins in HTC cells. ${ }^{43}$ Comparison of the patterns of

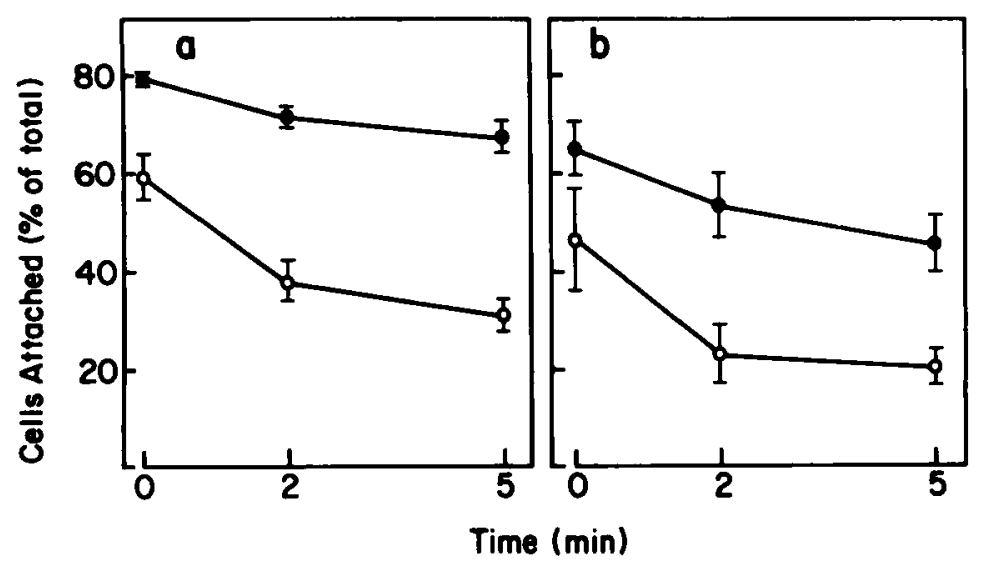

Figure 5. Dexamethasone induction of cellular adhesiveness in wild-type and variant HTC cells. Wild-type (a) or variant (b) HTC cells were incubated for 18 hours in serum-free medium containing bovine serum albumin in the presence $(O)$ or absence $(O)$ of $0.1 \mu \mathrm{M}$ dexamethasone. Adhesion was assayed as described by Fredin $e t$ al. ${ }^{9}$ Each point represents the mean \pm SEM of 9 experiments (a) and 4 experiments (b). (From Gelehrter $e t$ al. ${ }^{14}$ By permission of Cold Spring Harbor Laboratory.) 
synthesis of membrane and secretory proteins in dexamethasone-treated wild-type cells with those in variant cells with selective lesions in hormone responsiveness should help in both the identification and isolation of specific hormonally-induced proteins.

\section{ACKNOWLEDGMENTS}

I thank my colleagues: Patricia Barouski, Barbara Layton Fredin, Joanne Heaton, Roderick McDonald, Samuel Reichberg, William Risser, and Sarah Carlson Seifert for their contributions to these studies, and Judith Worley for secretarial assistance.

\section{REFERENCES}

1. Gelehrter, T. D. 1979. Glucocorticoids and membranes. In Glucocorticoid Hormone Action. J. D. Baxter and G. G. Rousseau, Eds.: 561-574. Springer-Verlag. Berlin.

2. Risser, W. L. \& T. D. GelehrTER. 1973. Hormonal modulation of amino acid transport in rat hepatoma cells in tissue culture. J. Biol. Chem. 248: 1248-1254.

3. Gelehrter, T. D., W. L. Risser \& S. B. Reichberg. 1975. Hormonal regulation of amino acid transport in rat hepatoma cells in tissue culture. In Gene Expression and Carcinogenesis in Cultured Liver, L. E. Gerschensen and E. B. Thompson, Eds.: 190-204. Academic Press. New York.

4. McDonald, R. A. \& T. D. Gelehrter. 1977. Glucocorticoid inhibition of amino acid transport in rat hepatoma cells. Biochem. Biophys. Res. Commun. 78: 1304-1310.

5. Heaton, J. H. \& T. D. Gelehr ter. 1977. Derepression of amino acid transport by amino acid starvation in rat hepatoma cells. J. Biol. Chem. 252: 2900-2907.

6. REICHBERG, S. B. \& T. D. GelehrTER. 1979. Glucocorticoid inhibition of multiple discrete amino acid transport systems in rat hepatoma cells. Submitted for publication.

7. Ballard, P. L. \& G. M. Tomkins. 1970. Glucocorticoid-induced alteration of the surface membrane of cultured hepatoma cells. J. Cell Biol. 47: 222-234.

8. Ballard, P. L. \& G. M. Tomkins. 1969. Hormone-induced modifications of the cell surface. Nature 224: 344-345.

9. Fredin, B. L., S. C. Seifert \& T. D. Gelehrter. 1979. Dexamethasone induction of adhesion in hepatoma cells: the role of plasminogen activator. Nature 227: 312-313.

10. Wigler, M., J. P. Ford \& I. B. Weinstein. 1975. Glucocorticoid inhibition of the fibrinolytic activity of tumor cells. In Proteases and Biological Control, E. Reich, D. B. Rifkin and E. Shaw, Eds.: 849-856. Cold Spring Harbor Laboratory. New York.

11. Carlson, S. A. \& T. D. Gelehrter. 1977. Hormonal regulation of membrane phenotype. J. Supramol. Struct. 6: 325-331.

12. Seifert, S. C. \& T. D. Gelehrter. 1978. Mechanism of glucocorticoid inhibition of plasminogen activator in rat hepatoma cells. Proc. Natl. Acad. Sci. USA 75: 6130-6133.

13. SEIFERT, S. C. \& T. D. GelehrTer. 1979. Isolation of variant rat hepatoma cells selectively resistant to glucocorticoid inhibition of plasminogen activator. J. Cell. Physiol. 99: 333342.

14. Gelehrter, T. D., S. C. Seifert \& B. L. Fredin. 1979. Glucocorticoid regulation of plasminogen activator in rat hepatoma cells. In Hormones and Cell Culture. R. Ross and G. Sato, Eds.: 259-267. Cold Spring Harbor Laboratory. New York.

15. Baxter, J. D. \& G. G. Rousseau, Eds. 1979. Glucocorticoid Hormone Action. SpringerVerlag. Berlin.

16. GelehrTer, T. D. 1976. Enzyme induction (three parts). New Engl. J. Med. 294: 522-526, $589-595,646-651$.

17. Christensen, H. N. 1975. Biological Transport. second edit. W. A. Benjamin. Reading, Pa.

18. Heaton, J. H. \& T. D. Gelehrter. 1980. Regulation of insulin responsiveness in rat hepatoma cells. Biochem. Biophys. Res. Commun. 92: 795-802.

19. Thompson, E. G., D. K. Granner \& G. M. Tomkins. 1980. Superinduction of tyrosine 
aminotransferase by actinomycin D in rat hepatoma (HTC) cells. J. Mol. Biol. 54: 159175.

20. Gelehrter, T. D. \& J. R. Emanuel. 1974. Hormonal regulation of protein degradation in hepatoma cells in tissue culture. Endocrinology 94: 676-684.

21. Epstein, D., S. Elias-Bishko \& A. Hershxo. 1975. Requirement for protein synthesis in the regulation of protein breakdown in cultured hepatoma cells. Biochemistry 14: 5199 5204.

22. LeE, K. L., J. R. ReEl \& F. T. KenNeY. 1970. Regulation of tyrosine $\alpha$-keto-glutarate transaminase in rat liver, IX. Studies of the mechanisms of hormonal inductions in cultured hepatoma cells. J. Biol. Chem. 245: 5806-5812.

23. Barker, K. L., K. L. Lee \& F. T. Kenney. 1971. Turnover of tyrosine transaminase in cultured hepatoma cells after inhibition of protein synthesis. Biochem. Biophys. Res. Commun. 43: 1132-1138.

24. SCHImke, R. T. 1975. Methods for analysis of enzyme synthesis and degradation in animal tissues. Methods Enzymol. 40: 241-266.

25. Samuels, H. H. \& G. M. Tomkins. 1970. Relation of steroid structure to enzyme induction in hepatoma tissue culture cells. J. Mol. Biol. 52: 57-74.

26. Rousseau, G. G. \& J. P. Schmit. 1977. Structure-activity relationships for glucocorticoids. J. Steroid Biochem. 8: 911-919.

27. McDonald, R. A. \& T. D. GelehrTer. Steroid structure and glucocorticoid inhibition of amino acid transport in rat hepatoma cells. Submitted for publication.

28. Sherman, M. R. 1979. Allosteric and competitive steroid-receptor interactions. In Glucocorticoid Hormone Action. J. D. Baxter and G. G. Rousseau, Eds.: 123-133. SpringerVerlag. Berlin.

29. Rousseau, G. G., J. D. Baxter, S. J. Higgins \& G. M. Tomkins. 1973. Steroid-induced nuclear binding of glucocorticoid receptors in intact hepatoma cells. J. Mol. Biol. 79. 539-554.

30. Wigler, M. \& I. B. Weinstein. 1975. A preparative method for obtaining enucleated mammalian cells. Biochem. Biophys. Res. Commun. 63: 669-674.

31. Gelehrter, T. D., R. A. McDonald \& P. Barouski. 1979. Role of the nucleus in the glucocorticoid regulation of membrane function. Clin. Res. 27: 448A.

32. MCDonald, R. A. \& T. D. Gelehrter. Requirement for the nucleus in the glucocorticoid regulation of membrane transport. XIth International Congress of Biochemistry Abs. 116-S156: 624.

33. Ivarie, R. D., W. J. W. Fan \& G. M. Tomkins. 1975. Analysis of the induction and deinduction of tyrosine aminotransferase in enucleated HTC cells. J. Cell Physiol. 85: 357-364.

34. RigGs, T. R. 1970. Hormones and transport across cell membranes, In Biochemical Action of Hormones, G. Litwack, Ed. 1: 157-208. Academic Press. New York.

35. Reich, E., D. B. Rifkin \& E. Shaw, Eds. 1975. Proteases and Biological Control. Cold Spring Harbor Laboratory. New York.

36. Roblin, R., I. N. Chou \& R. H. Black. 1975. Proteolytic enzymes, cell surfaces changes, and viral transformation. Adv. Cancer Res. 22: 203-260.

37. HYNES, R. O. 1974. Role of surface alterations in cell transformation: the importance of proteases and surface proteins. Cell 1: 147-156.

38. Shimada, T., N. Colburn, S. A. Carlson \& T. D. Gelehrter. 1977. Unpublished observations.

39. Jones, P., W. Benedict, S. Strickland \& E. Reich. 1975. Fibrin overlay methods for the detection of single transformed cells and colonies of transformed cells. Cell 5: 323-329.

40. Yamamoto, K. R., U. Gehring, M. R. Stampfer \& C. H. Sibley. 1976. Genetic approaches to steroid hormone action. Recent Prog. Horm. Res. 32: 3-32.

41. Sibley, C. \& K. Yamamoto. 1977. Mechanisms of resistance of mouse lymphoma cells to glucocorticoids, In Glucocorticoid Hormone Action. J. D. Baxter and G. G. Rousseau, Eds. Springer-Verlag. Berlin.

42. Thompson, E. B., D. K. Granner, T. D. Gelehrter, J. Erickson \& G. L. Hager. 1979. Unlinked control of multiple glucocorticoid-induced processes in HTC cells. Mol. Cell. Endocrinol. 15: 135-150.

43. Baumann, H., T. D. Gelehrter \& D. Doyle. Dexamethasone regulates the program of secretory glycoprotein biosynthesis in hepatoma tissue culture (HTC) cells. Submitted for publication. 